\title{
Early light adaptation in young, middle-aged, and older observers
}

\author{
JOSEPH F. STURR and KATHERINE L. CHURCH \\ Syracuse University, Syracuse, New York
}

and

\author{
HARVEY A. TAUB \\ Veterans Administration Medical Center, Syracuse, New York
}

\begin{abstract}
Early light adaptation (ELA) was examined in young, middle-aged, and older observers in two experiments employing a criterion-free procedure. All subjects had corrected visual acuity of at least 20/30 and no history of ocular pathology. A white, $1.2^{\circ}, 50$-msec test flash (TF) was presented in the center of a white, $8.2^{\circ} \times 7.4^{\circ}, 1,000$-msec photopic adapting field (AF) through an artificial pupil to the left temporal retina. Our results showed a systematic slowing in the time course of ELA: the young group, a steep recovery function; the middle group, a less steep function; and the oldest group, a reversal of the function. The individual data of the young and older observers were characteristic of their groups, but the middle-aged observers showed interesting transitional functions. The possible selective loss of channels in the aging visual system is discussed.
\end{abstract}

There is a great deal of evidence from a number of laboratories indicating slower responses in the aging visual system. This evidence has included measures of flicker fusion (McFarland, Warren, \& Karis, 1958; Misiak, 1947), backward masking (Walsh, 1976), visual persistence (Kline \& Orme-Rogers, 1978), and temporal integration (Eriksen, Hamlin, \& Breitmeyer, 1970).

In this study, we employed Crawford's (1947) early light adaptation (ELA) paradigm to examine temporal changes in the aging visual system. The ELA function has often been considered to be a psychophysical representation of neural activity to the onset of a visual stimulus (on-response). When a large adapting field (AF) is turned on, detection threshold is first high and then rapidly declines to an asymptotic level. This transient threshold rise is strongly influenced by the rise time of the AF. Matsamura (1976) showed that an abrupt onset of the AF is required to cause the transient overshoot. Furthermore, it has been shown that the size of the AF is critical in determining the size of the transient overshoot. Teller, Matter, Phillips, and Alexander (1971) showed that a large AF caused a large on-response. For a smaller background, the on-response was absent and the time course of the ELA function was much slower.

Based upon the results of these studies, Sturr, Kelly,

This research was supported by NIA Grant AG04465 to J.F.S. and by the Behavioral Research Directorate of the U.S. Army H.E.L. A preliminary report was presented at the May 1984 meetings of the Association for Research in Vision and Ophthalmology.

J. F. Sturr's and K. L. Church's mailing address is: Department of Psychology, Syracuse University, 473 Huntington Hall, 150 Marshall St., Syracuse, NY 13210. H. L. Taub's mailing address is: V.A. Medical Center, 800 Irving Ave., Syracuse, NY 13210.
Kobus, and Taub (1982) used a large AF with an abrupt onset in order to provide optimal stimulus conditions for generating an on-response. They found the characteristic function for two observers in their 20s: on-response at 0 stimulus onset asynchrony (SOA) with a subsequent threshold decline to an asymptotic level at longer SOAs. However, they found that the on-response was attenuated and the time course of the ELA function was slower for two observers in their 40s. The purpose of the present study was to further investigate age-related changes in the ELA function. The study consisted of two experiments that spanned a larger age range than that used in Sturr et al. (1982). Experiment 1 was conducted to determine which SOAs were most sensitive to age changes. Two SOAs were then selected to investigate these age changes in a larger number of observers in Experiment 2.

\section{EXPERIMENT 1}

\section{Method}

Subjects. Four young, three middle-aged, and three older observers with mean ages of 27,48 , and 65 years, respectively, vollunteered to participate in the experiment. The observers were either professors or graduate students in the Psychology Department at Syracuse University. All observers had uncorrected or corrected visual acuities of $20 / 30$ or better in the left eye, as measured on a Bausch and Lomb Orthorater. Observers had no known ocular pathology.

Apparatus. Stimuli were presented through a four-channel look-in tachistoscope (Iconix Model 6137-4). The adapting and test fields were provided by white light projected from two Kodak Ektagraphic Model E-2 Carousel projectors upon ground-glass screens of separate channels of the tachistoscope. The spatial arrangement of stimuli is illustrated in Figure 1. A circular, $1.2^{\circ}$ test field (TF) was centered upon a rectangular, $8.2^{\circ}$ (horizontal) $\times 7.4^{\circ}$ (vertical) AF. A red LED placed in a third channel of the tachistoscope 


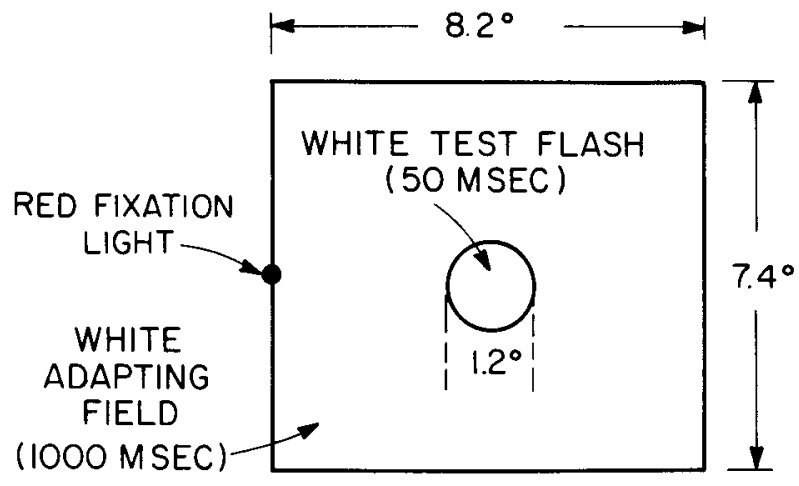

Figure 1. Spatial arrangement of stimuli.

served as a 5-min fixation point. It was positioned tangent to the left border of the AF and centered vertically. The fixation allowed the $\mathrm{AF}$ and $\mathrm{TF}$ to be presented at $4.1^{\circ}$ in the temporal retina of the observer's left eye. Observers looked into the tachistoscope through a $2-\mathrm{mm}$ artificial pupil.

Luminance of the AF was controlled by fixed Kodak No. 96 neutral density filters. Luminance of the TF was controlled by neutral density filters arranged in the Carousel tray, providing a 4-log unit range of luminance in $0.1 \log$ unit steps. Duration of the $A F$ and TF and the relative onset between AF and TF (SOAs) was controlled by delivering calibrated pulses from a Digital PDP-8/f computer to electronic shutters (Lafayette Model 93011 and Uniblitz Model 225L2A3X5) attached to the barreis of the projectors. The calibration procedures for the luminance, illuminance, and duration of the AF and TF were the same as those described in an earlier paper (Sturr et al., 1982). AF and TF durations were 1,000 and $50 \mathrm{msec}$, respectively, with $1.5-\mathrm{msec}$ rise times. The AF was $3.51 \mathrm{~mL}$, or 35.1 photopic trolands (Td), through the artificial pupil. Stray light from the projectors and from the fixation spot in the system provided a constant retinal illuminance of $0.1 \mathrm{Td}$.

Procedure. Prior to each session, the observer adjusted the artificial pupil so that it allowed a full view of the AF through the viewing hood. The AF was then turned off, and the observer spent 5 min adapting to the fixation spot. A temporal, two-alternative, forced-choice (2AFC) staircase procedure (Wetherill \& Levitt, 1965) was used to measure detection thresholds. The temporal sequence of stimulation is illustrated in Figure 2. At the end of each trial, the observer's response ( $R$ ) triggered a feedback tone indicating the actual interval in which the TF was presented. Two correct detection trials resulted in a $0.1 \mathrm{log}$ unit decrement, and one miss caused a $0.1 \mathrm{log}$ unit increment in TF intensity. This procedure continued until 20 staircase reversals had occurred; it yielded a $71 \%$ hit rate. Two such threshold measures were determined for 0 -, $10-, 20-, 30-, 40-, 50-, 80-$, and 100 -msec SOAs over six separate sessions on 6 separate days. Two or three SOAs were run during each session. Order of SOA presentation was randomized across subjects and sessions. The total duration of one session, including a 5-min break betwen SOAs, was approximately $45 \mathrm{~min}$.

\section{Results}

Group mean log relative thresholds are plotted as a function of SOA in Figure 3. The young observers' threshold peaked at 0 SOA and monotonically decreased as SOA increased. The middle-aged observers showed an increase in threshold up to about $40-\mathrm{msec}$ SOA, followed by a threshold decline with longer SOAs. The shape of the older observers' function was similar to that of the middleaged observers. However, thresholds were shifted upwards and the peak of the function was flatter. The results of Experiment 1 are consistent with the earlier findings of Sturr et al. (1982) and extend their results by showing that the older observers have an inverted ELA function similar to that of the middle-aged observers. These results were then used to establish which SOAs were most sensitive to age changes. We thus selected two SOAs, 0 and 40 , to be tested on a larger sample of naive observers in Experiment 2.

\section{EXPERIMENT 2}

\section{Method}

Subjects. Twenty-four observers were divided into three equal groups with age ranges of 21 to 25 years (mean $=22.8$ ), 35 to 51 years $($ mean $=43.4)$, and 60 to 74 years $($ mean $=64.3)$. The young observers, four male and four female, were Syracuse University undergraduates fulfilling a requirement for an introductory psychology course. The middle-aged, four male and four female, and older observers, three male and five female, were recruited from the community or from a pool of volunteer workers at the Syracuse Veterans Administration Hospital. All subjects were paid for their participation. Screening for acuity and pathology was the same as in Experiment 1.

Apparatus. The same stimuli and apparatus were used as described for Experiment 1.

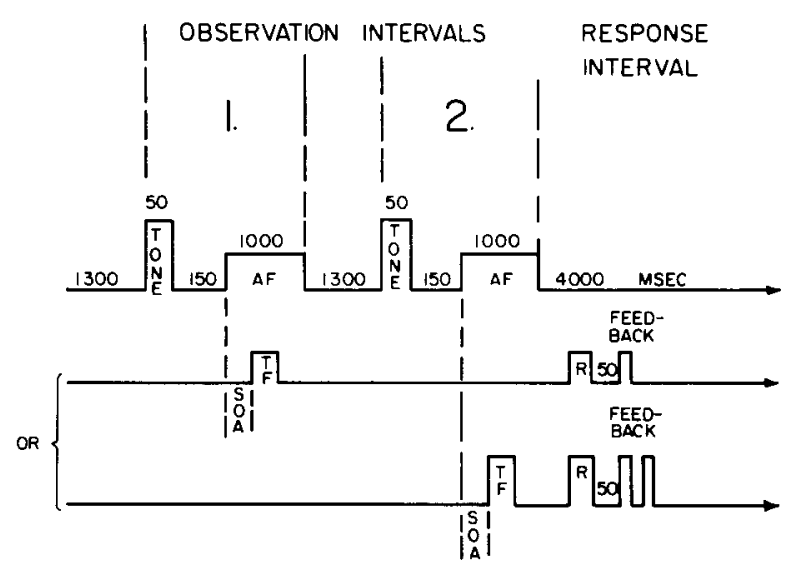

Figure 2. Timing of stimuli and 2 AFC method with feedback.

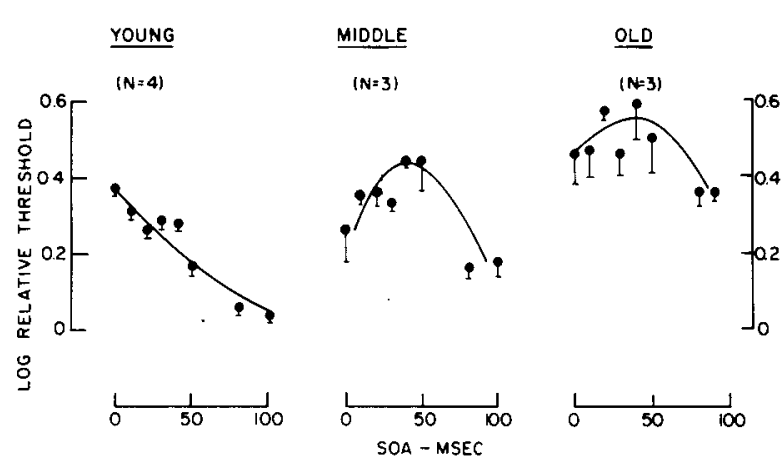

Figure 3. ELA functions for the three age groups. Error bars = $1 \mathrm{SE}$, ordinate = TF threshold, and abscissa = delay between TF and AF onsets (SOA). 
Procedure. Threshold measures were determined for each observer at 0 - and $40-\mathrm{msec}$ SOAs. The experiment consisted of three 45-min sessions on 3 separate days. The first session consisted of practice on both SOAs. In the remaining sessions, two threshold measures on one SOA were run per session with a 5-min break between measures. SOA order was counterbalanced across sessions. The same 2AFC procedure was used as in Experiment 1.

\section{Results}

A group $\times$ sex $\times$ SOA split-plot ANOVA yielded significant main effects of group $[\mathrm{F}(2,18)=9.55, \mathrm{p}<.01]$ and $\operatorname{SOA}[F(2,18)=4.62, \mathrm{p}<.05]$. The interaction between group and SOA was also significant $[\mathrm{F}(2,18)=$ 13.27, $\mathrm{p}<.01]$. This interaction is illustrated in Figure 4 , which shows group mean relative thresholds plotted as a function of SOA. The three curves show a systematic shift in the time course of the ELA function across the three age groups. The ELA function for the young observers showed a steeper recovery than that of the middleaged observers, whereas the older observers showed a reversal of the ELA function. Simple main effect and Scheffé analyses were used to further evaluate this interaction. No significant differences between age groups were found at $0-\mathrm{msec}$ SOA. However, at $40-\mathrm{msec}$ SOA, the young observers' thresholds were significantly lower than the thresholds for the older observers $[\mathrm{t}(14)=3.56$, $\mathrm{p}<.01]$. The middle-aged observers did not differ significantly from either group in the 40-msec condition. Comparisons within each age group indicated that the young observers' 40-msec mean threshold was significantly lower than their 0 -msec mean threshold $[\mathrm{F}(1,14)$ $=12.98, \mathrm{p}<.05$ ], and the older observers' 40 -msec threshold was significantly higher than their 0 -msec threshold $[F(1,14)=8.24, p<.05]$. The mean thresholds of the middle-aged group did not differ significantly between the 0 - and 40 -msec SOAs.

In order to determine whether the mean thresholds were characteristic of individual performance, we plotted the individual data in Figure 5. In this figure, individual thresholds were plotted as a function of SOA. All but one

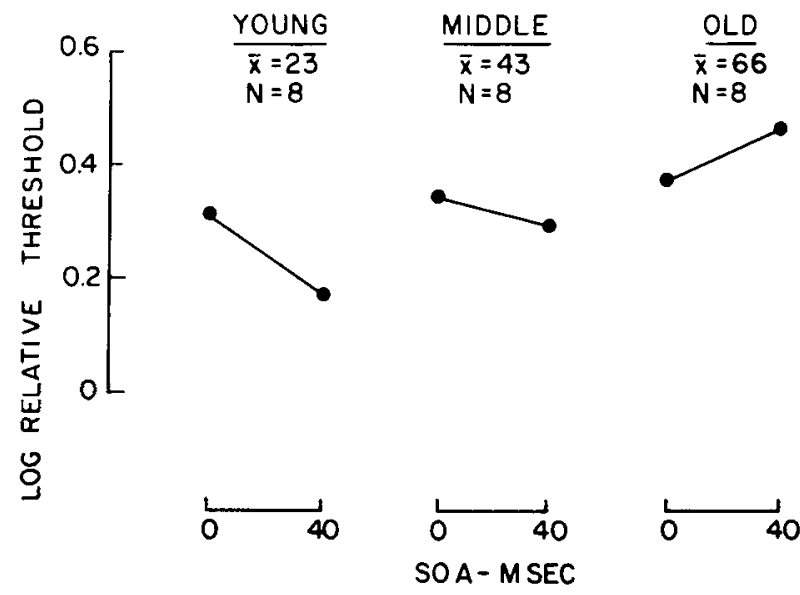

Figure 4. ELA thresholds measured at 0 - and $40-\mathrm{msec}$ SOAs for the three age groups.

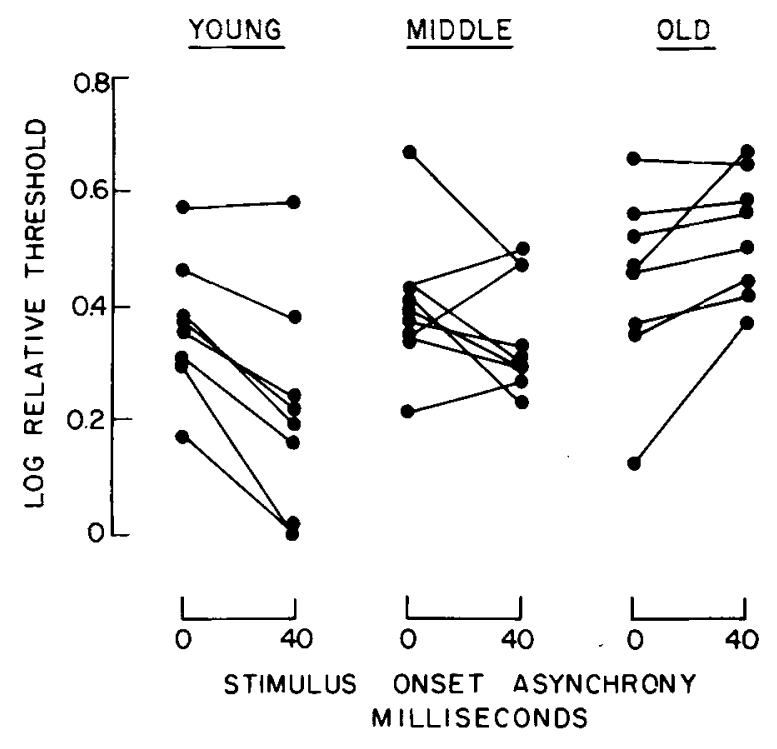

Figure 5. Data for individual observers.

young observer showed the characteristic declining function, and all but one older observer showed the increasing function. Five of the middle-aged observers performed in a way that was typical of the young observers, and three did so in a way that was typical of the older observers.

Since 2AFC tasks require a comparison of sensory impressions in two temporal intervals, we were concerned about possible confounding of memory upon detection rates in each interval. Therefore, a group $\times$ sex $\times$ SOA $X$ interval split-plot ANOVA was performed on hit rate. There were no main effects or interactions.

\section{DISCUSSION}

The results support the earlier findings of an agedependent ELA function (Sturr et al., 1982). A reduction in the older observers' on-response and a slower time course than that of the young observers were found in Experiment 1. Experiment 2, with a larger number of observers, confirmed that the older observers have slower ELA functions. The findings of the middle group are less clear, as indicated by the opposite trends of the group functions in Experiment 1 and Experiment 2. However, this discrepancy in trends across experiments is consistent with the variability in trends observed for the individual data within each experiment. ${ }^{1}$ It would appear that the middle-age range may represent a transitional group with functions characteristic of either the young or the old. Further investigation is required to determine what factors are responsible for the shape of the middleaged observers' ELA function.

The underlying mechanism or mechanisms causing the age-dependent on-response loss is unknown. As mentioned in the introduction, there are certain stimulus conditions which can eliminate or reduce the on-response in young observers. Furthermore, Mitov, Vassilev, and 
Manahilov (1981) have shown that the on-response is severely attenuated by a high-spatial-frequency masking stimulus, and Green (1981) showed that a low-spatialfrequency test will reveal the on-response, but a highspatial-frequency test will not. Together, these studies are consistent with the view that an onset of an AF can trigger two different responses: a transient type of response or a sustained type of response.

Other investigators (Breitmeyer \& Ganz, 1976; Kulikowski \& Tolhurst, 1973) have argued that these two distinct responses are mediated by two distinct channels in the visual system. ${ }^{2}$ The transient channel is maximally sensitive to low spatial frequencies and responds in a transient manner. The sustained channel responds maximally to the high spatial frequencies, has a longer latency, and continues to respond for a longer period of time. It is reasonable to hypothesize that the transient overshoot or on-response is mediated by the transient visual channel. Any manipulation in stimulus conditions that would weaken the transient channel response, such as the use of a high-spatial-frequency adapting stimulus, would also result in the loss or reduction of the on-response in the ELA experiment. The results of Matsamura (1976) and of Teller et al. (1971) are also consistent with this notion.

Kline and Schieber (1981) have recently suggested that age-related slowing in visual function may be caused by a shift in sensitivity from transient to sustained mechanisms. It is not clear at present whether all of the paradigms, including ours, that have demonstrated an agerelated slowing of visual function might be assessing common underlying mechanisms. It is interesting to speculate that the loss of the on-response in the aging visual system may also be caused by a loss of transient channels. We feel that in future experiments appropriate spatial frequency manipulations must be used in order to provide a critical test of the transient/sustained hypothesis.

\section{REFERENCES}

BREITMEYER, B. G., \& GANZ, L. (1976). Implications of sustained and transient channels for theories of visual pattern masking, saccadic suppression, and information processing. Psychological Review, 83, 1-36.

CraWford, B. H. (1947). Visual adaptation in relation to brief conditioning stimuli. Proceedings of the Royal Society, B, 134, 283-302.

Eriksen, C. W., Hamlin, R. M., \& Breitmeyer, R. G. (1970). Tem- poral factors in visual perception related to aging. Perception \& Psychophysics, 7, 354-356.

GreEN, M. (1981). Spatial frequency effects in masking by light. $V i$ sion Research, 21, 861-866.

KLINE, D. W., \& ORME-Rogers, C. (1978). Examination of stimulus persistence as a basis for superior visual identification performance among older adults. Journal of Gerontology, 33, 76-81.

KLINE, D. W., \& SChIEBER, F. (1981). Visual aging: A transient/sustained shift? Perception \& Psychophysics, 29, 181-182.

Kulikowski, J. J., \& Tolhurst, D. J. (1973). Psychophysical evidence for sustained and transient detectors in human vision. Journal of Physiology, 232, 149-162.

LenNiE, P. (1980a). Parallel visual pathways: A review. Vision Research, 20, 561-594

LenNie, P. (1980b). Perceptual signs of parallel pathways. Philosophical Transactions of the Royal Society, B, 290, 23-37.

MatSamura, M. (1976). Visual masking by luminance increment and decrement: Effects of rise time and decay time. Tohoku Psychologia Folia, 35, 104-114

McFarland, R. A., WarRen, A. B., \& Karis, C. (1958). Alterations in critical flicker frequency as a function of age and light:dark ratio. Journal of Experimental Psychology, 56, 529-538.

MisiaK, H. (1947). Age and sex differences in critical flicker frequency. Journal of Experimental Psychology, 37, 318-332.

Mitov, D., VAssilev, A., \& Manahilov, V. (1981). Transient and sustained masking. Perception \& Psychophysics, 30, 205-210.

Sturr, J. F., Kelly, S. A., Kobus, D. A., Taub, H. A. (1982). Age-dependent magnitude and time course of early light adaptation. Perception \& Psychophysics, 31, 402-404.

Teller, D. Y., Matter, C., Phillips, W. D., \& Alexander, K. (1971). Sensitization by annular surrounds: Sensitization and masking. Vision Research, 11, 1445-1458.

WaLSH, D. A. (1976). Age differences in central perceptual processing: A dichoptic backward masking investigation. Journal of Gerontology, 31, 178-185.

WETHERILL, G. B., \& LEVITT, H. (1965). Sequential estimation of points on a psychometric function. British Journal of Mathematical and Statistical Psychology, 18, 1-10.

\section{NOTES}

1. As pointed out for Experiment 2, the individual data for the middleaged observers in Experiment 1 also split, with two showing functions characteristic of the old and one showing a function characteristic of the young. We should also note that the two subjects that showed the old function were the same observers (J.F.S. and H.A.T.) used in the old group in Sturr et al. (1982).

2. Whether or not these channels are dichotomous is unclear. For a review critical of the sustained-transient dichotomy, see Lennie (1980a, 1980b). Green (1981) presents evidence that reconciles the two extreme viewpoints.

(Manuscript received December 26, 1984; accepted for publication April 17, 1985.) 